\title{
ANÁLISE ESPACIAL DAS ÁREAS VERDES DE BELO HORIZONTE (MG)
}

\author{
SPATIAL ANALYSIS OF GREEN AREAS OF BELO HORIZONTE CITY, MINAS \\ GERAIS STATE (MG), BRAZIL
}

\author{
Antoniel Silva Fernandes ${ }^{1}$, Altino Barbosa Caldeira²
}

\begin{abstract}
RESUMO
O objetivo deste trabalho foi pesquisar as áreas verdes do município de Belo Horizonte - MG. Para isso foi identificado: a importância, origem, uso e distribuição espacial dos fragmentos vegetais. Para atender ao proposto, realizou-se o mapeamento, a caracterização e a classificação das áreas verdes não urbanizadas e/ou não ocupadas, identificando-se as suas condições de apropriação. Os 104 espaços verdes investigados, distribuídos de forma aleatória pelo município, correspondem a $10 \%$ do território total e são constituídos, em sua maioria, por parques municipais de dimensões muito pequenas (em média de um a três hectares). Observou-se que existe pouca possibilidade de conexão entre eles, sem a realização de grandes intervenções urbanísticas. Entretanto, entre as áreas verdes investigadas, aquelas situadas ao sul do município de Belo Horizonte formam um "eixo verde" com as áreas situadas no sentido sudoeste/ leste, nas vertentes da Serra do Curral. Outro "eixo verde" se forma na Regional Administrativa Nordeste, sentido noroeste. Este estudo possibilitou ainda, indicar conexões de áreas verdes em terrenos não ocupados, e que, portanto, são áreas potenciais para a criação de parques ou demais unidade de conservação, e que podem vir a ser destinadas à preservação ambiental.
\end{abstract}

Palavras-chave: Paisagem; Paisagem urbana; Eixos verdes.

\section{ABSTRACT}

The aim of this study was to research the green areas of Belo Horizonte - MG. For this, it was identified: the importance, origin, use, and spatial distribution of vegetation patches. For this proposal, mapping, characterization, and classification of green non-urbanized and/or not occupied areas were carried out, identifying their appropriation conditions. The total of 104 green spaces investigated, randomly distributed by the municipality, accounts for $10 \%$ of the total territory and are composed mostly by very small municipal parks (one to three hectares on average). It was observed that there are few possibilities of connection among them, without performing large urban interventions. However, among the investigated green areas, those located south of the city of Belo Horizonte form a "green axis" with the areas situated towards west/east, in the slopes of the Serra do Curral (Curral mountain range). Another "green axis" is formed on the northeast Administrative Regional, at northwest direction. This study also enabled to point out green areas connection in unoccupied spaces, which are, therefore, potential for the creation of parks or other protected area, and are likely to be aimed at environmental preservation.

Keywords: Landscape; Urban landscape; Green axes.

Recebido em 05.07.2016 e aceito em 30.08.2016

1 Geógrafo, Mestre no programa de pós-graduação em Geografia - Tratamento da Informação Espacial da PUC-Minas. Especialista em Licenciamento e Impacto Ambiental - PUC-Minas, professor do curso de Engenharia Ambiental da Newton Paiva e consultor do Instituto Brasileiro de Desenvolvimento e Sustentabilidade - IABS, Belo Horizonte - MG, e-mail: geoansf@yahoo.com.br

2 Arquiteto, Doutor (PhD) pela Universidade de Sheffield/ Inglaterra, professor do curso de Arquitetura e Urbanismo e do Programa de Pós-Graduação em Geografia - Tratamento da Informação Espacial da PUC-Minas, Belo Horizonte - MG, e-mail: altinocaldeira@gmail.com 


\section{INTRODUÇÃO}

Uma das formas de garantir e promover a qualidade do ambiente urbano é preservar e manter as áreas verdes existentes, por meio da criação de parques e pelo cuidado há proteção aos cursos d'água em seu leito natural, contribuindo para a diminuição das ocorrências de inundações e proporcionando espaços de lazer e convívio.

As áreas verdes em ambientes urbanos são os espaços livres de construção onde o elemento fundamental de composição é a vegetação, e que agregam valor a este ambiente por possuírem os seguintes atributos principais: ecológico-ambiental, estético e de lazer. De acordo com Buccheri Filho e Nucci (2006) canteiros, pequenos jardins de ornamentação, rotatórias e arborização não podem ser considerados áreas verdes, mas sim, "verde de acompanhamento viário" que, com as calçadas (sem separação total em relação aos veículos) pertencem à categoria de espaços construídos ou espaços de integração urbana.

Ainda segundo Buccheri Filho e Nucci (2006) as áreas verdes são fundamentais e também necessárias para propiciar condições de vida a todas as espécies animais e vegetais, como integrantes da biodiversidade no ambiente urbano. Mazzei, Colesanti e Santos (2007) destacam a importância da temática para permite entender melhor a qualidade, a quantidade, a distribuição e os efeitos destas áreas para os citadinos, para o tecido urbano e para a própria cidade.

A análise espacial de um problema ou tema de pesquisa consiste em visualizar espacialmente (sobretudo através de mapas) um conjunto de dados, de modo a elucidar respostas sobre padrões espaciais e verificar ocorrências ou evidências, criando, a partir daí, possibilidades, perspectivas e propostas para o problema, ou o tema inicial. Para Lang e Blaschke (2009) o estudo da paisagem, na análise espacial, foca nas feições estruturais observáveis e mensuráveis na paisagem, permitindo caracterizar as suas condições, seu desenvolvimento e sua mudança temporal.

Em Belo Horizonte, capital de Minas Gerais, embora a Prefeitura Municipal disponha de amplo banco de dados alfanumérico e espacial sobre as áreas verdes, tais informações encontram-se ainda muito fragmentadas em relação às necessidades da análise espacial desses ambientes (COSTA, 2009). Observa-se que essas informações encontram-se ainda incompletas, desatualizadas e distribuídas aleatoriamente em bancos de dados diversos, o que em muito inviabiliza um trabalho mais efetivo de gestão dessas áreas, e acaba trazendo diversos e graves prejuízos à qualidade do ambiente urbano.

Neste contexto, se torna necessário avaliar a distribuição das áreas verdes de Belo Horizonte, visando contribuir com a Prefeitura Municipal para o aperfeiçoamento da sua capacidade de gestão. 
Nota-se também a existência de áreas residuais não ocupadas, desconectadas de um conjunto de áreas verdes. Desta forma, este estudo possibilita ainda avaliar a distribuição desses espaços com vistas à constituição de um mosaico possível de ser interligado, e que poderia vir a trazer benefícios consistentes para a capital. Nesse sentido, cabe citar, dentre outras, propostas similares desenvolvidas para Curitiba (BUCCHERI FILHO; NUCCI, 2006) e Goiânia (MOREIRA; SILVA, 2012).

Deste modo, esta pesquisa visa um mapeamento das áreas verdes em centros urbanos, identificando a sua importância para a cidade, buscando informar a sua origem e destinação, assim como a distribuição espacial dos fragmentos vegetais de modo a entendê-la em sua totalidade.

\section{MATERIAL E MÉTODOS}

O foco da pesquisa é voltado para a cidade de Belo Horizonte/ MG (Figura 1). Para se alcançar o objetivo proposto foi realizada a caracterização e a classificação das áreas verdes, das áreas não urbanizadas e/ ou não ocupadas da Capital mineira. Também foi realizada a identificação das condições de apropriação dessas áreas e a possibilidade de criação de um sistema de valorização dessas áreas verdes. Propõe-se, desse modo, uma integração sistêmica, de forma a buscar privilegiar os eixos verdes e, consequentemente, uma relação adequada entre as áreas verdes existentes e os habitantes, de modo a oferecer-Ihes melhores condições de lazer e um estudo voltado para a sua preservação.

Nesta pesquisa foram selecionadas as áreas verdes já consolidadas e institucionalizadas pelo município, como os parques e demais áreas já protegidas pela esfera pública, bem como, os espaços coletivos constituídos de fragmentos vegetais relevantes, situados em universidades, hortos, zoológicos e jardins botânicos. Durante esta pesquisa foram ainda identificados espaços privados com vegetação significativa e já destinados à preservação, que foram incorporados ao universo de estudo.

Posteriormente, buscou-se incorporar outras áreas verdes que apresentam a possibilidade de serem preservadas pela sua importância ecológica, ou de conexão delas com outros fragmentos verdes. Não foram considerados como foco deste estudo os cemitérios, que também são caracterizados pelo poder público como áreas verdes urbanas. 


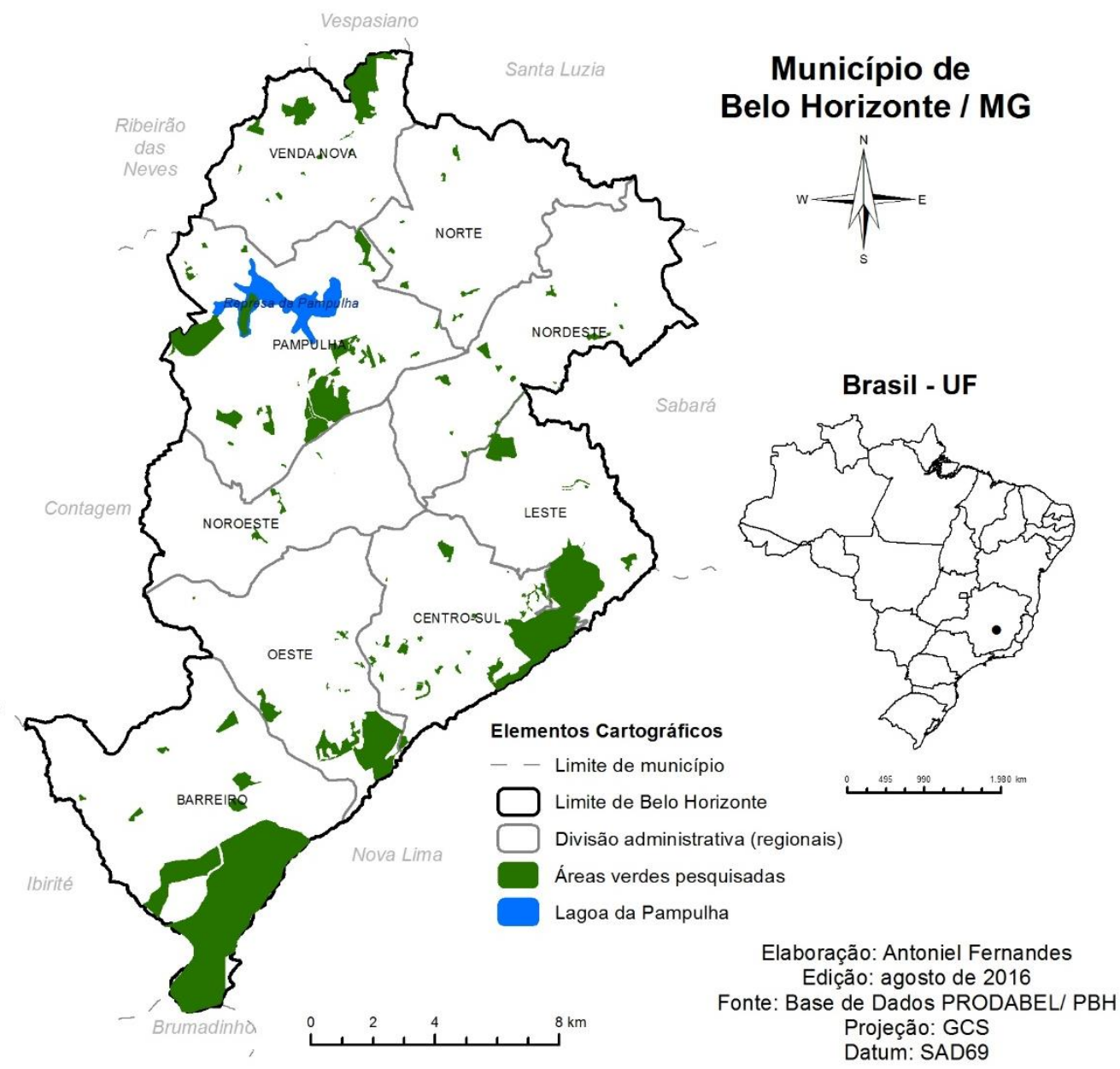

Figura 1. Mapa do Município de Belo Horizonte/ MG com as nove Regionais Administrativas Figure 1. Map of the Municipality of Belo Horizonte/MG with the nine Administrative Regions

A metodologia consistiu no levantamento espacial das áreas verdes de Belo Horizonte por meio da construção de um banco de dados geográfico, que agrupam os dados cartográficos a serem utilizados na elaboração dos mapas temáticos. Para isto foram empregadas técnicas de geoprocessamento, com auxílio dos softwares ArcGis (versão 10.1), Maplnfo (versão 6.5) e Quantum Gis (versão 1.8.0). As bases de dados geográficas foram fornecidas, pela Companhia de Processamento de Dados (PRODABEL); pela Secretária Municipal Adjunta de Planejamento Urbano (SMAPU) e pela Fundação de Parques Municipais (FPM), órgãos vinculados à PBH. Os dados foram tratados espacialmente, o que possibilitou averiguar a distribuição das áreas verdes institucionalizadas no território do município e a disposição destes espaços na trama do tecido urbano. Em seguida, essas informações foram utilizadas para o cadastramento e mapeamento destas áreas.

Os softwares utilizados pertencem ao Laboratório de Estudos Urbanos e Regionais do Programa de Pós-graduação em Geografia - Tratamento da Informação Espacial da Pontifícia Universidade Católica de Minas Gerais (PUC-Minas). Posteriormente, estes mesmos programas 
de geoprocessamento (Arcgis e Quantum Gis) auxiliaram a execução dos mapas das áreas verdes existentes no município. A base de dados da FPM/ $\mathrm{PBH}$, que continha a relação de todos os parques municipais da Capital foi sistematizado e, estes espaços foram classificados em categorias.

Para o cálculo de área apresentado em resultados e discussões foi realizado o agrupamento dos polígonos das áreas verdes no programa Arcgis utilizando-se o método de "quebra natural" (natural break).

Foi elaborado um mapa exploratório hipotético com o objetivo de criar círculos de proteção no entorno das áreas verdes para analisar e identificar a influência desses espaços nos ambientes urbanos. Consideraram-se, para isso, as condições biológicas que possibilitam interações entre as áreas verdes existentes avaliando-se os ambientes naturais e os benefícios sociais que estes espaços proporcionam para os citadinos. Entre estes benefícios encontram-se a qualidade térmica e do ar em seu entorno, e sua utilização para lazer e outras atividades sociais (SHAMS; GIACOMELI; SUCOMINE, 2009; MAZZEI; COLESANTI; SANTOS, 2007; COSTA; COLESANTI, 2011).

Cabe ressaltar, que a criação destes círculos como modelos de análise e identificação devem ser relativizados, pois estes limites não podem ser traduzidos para a realidade com exatidão, em função das declividades do terreno, do adensamento populacional e pela existência, em alguns casos, de barreiras físicas. Ao tratar deste assunto Lang e Blaschke (2009) afirmam que "o princípio da imprecisão, de forma alguma pode ser visto como uma insuficiência científica ou falha técnica; pelo contrário, representa uma aproximação adicional à realidade, na qual separações rigorosas e agregações inequívocas frequentemente não são possíveis". Desse modo, foram utilizados:

- um raio de 100 metros, propostos por Ribeiro et al (2009) e Tabarelli et al. (2010), para avaliar as conectividades funcionais dos elementos biológicos;

- um raio de 300 metros, recomendado por Feliz (2013), como indicador de melhoria da qualidade de vida urbana, e

- um raio de 600 metros, utilizado por urbanistas e planejadores para indicar a distância máxima que uma pessoa deve caminhar entre um destino e outro (KRIER; CARVALHO, 1999; COLIN, 2013).

\section{Categorização das Áreas Verdes}

A organização dos espaços verdes em categorias foi baseada na metodologia proposta por Mazzei, Colesanti e Santos (2007), Buccheri Filho e Nucci (2006), Costa et al. (2009), Bargos e Matias (2011) e Moreira e Silva (2012) e adaptadas para as áreas verdes da cidade de Belo 
Horizonte. Isto ocorreu com o auxílio de imagens da cidade feitas pelo satélite quickbird na escala de 1:5.000 (de 2008) fornecido pela PRODABEL. Foram também feitas consultas ao Google Earth e ao Street view, e ainda, ao site eletrônico da Fundação de Parques Municipais. Desta forma, foi possível classificar as áreas verdes em três categorias:

1. Conservação da Paisagem: para os espaços destinados a resguardar os fragmentos vegetais remanescentes na cidade e que não são constituídos por espécie exóticas, ruderais ou ornamentais em sua maioria. Parte destes espaços já é, ou podem ser, utilizados para o lazer;

2. Áreas de Lazer: para os espaços públicos destinados exclusivamente à recreação, prática de esporte, ornamentação. Espaços onde quase não há fragmentos vegetais remanescentes ou que predomine vegetação exótica ou ornamental. Estes espaços podem ser entendidos como praças públicas, contudo, são tratados pela Prefeitura como parques, de acordo com a legislação que os criaram;

3. Reabilitação de Paisagem Degradada: para os espaços em estágio avançado de perda da estrutura física como aqueles que possuem processos erosivos, solo exposto, ausência de vegetação, poluição hídrica ou predominância de vegetação ruderal. Mesmo nessas condições foram transformados em áreas protegidas pelo município, também por meio da criação de parques urbanos. Estes espaços foram subcategorizados, com a possibilidade de virem a ser recuperados e terem uma destinação, no futuro, que podem ser:

- Para conservação da paisagem: aqueles espaços onde há projeto elaborado pela PBH destinando-os para a preservação;

- Exclusivo para áreas de lazer: aqueles espaços que, desempenha a suas condições atuais, podem ser destinados a espaços exclusivos para o lazer, como uma praça pública;

- Possibilidade de conservação da paisagem: espaços onde a intenção da municipalidade ainda não é evidente quanto à sua destinação, se somente para o lazer ou também para a conservação das áreas verdes, apesar de já serem considerados parques municipais. Estes espaços dependem da elaboração de projetos que irão evidenciar a sua utilização à preservação.

Essas categorias foram desenvolvidas observando-se as áreas verdes levantadas para esta pesquisa, ou seja, não englobam todos os espaços verdes existentes em Belo Horizonte, pois não incluí as áreas verdes situadas ao longo das vias urbanas, como as áreas verdes das rotatórias, canteiros centrais, dentre outros, e as áreas verdes dos equipamentos urbanos institucionais como presentes nas escolas, creches, postos e centros de saúde. 
Cabe ressaltar, que na etapa de classificação das áreas verdes para este estudo foi considerado o estado atual de cada área verde e não a situação do espaço no momento de sua criação, como presente na base de dados.

\section{Etapa de Campo}

Após a classificação das áreas verdes institucionalizadas, foi realizado o trabalho de campo buscando-se conferir e validar as áreas verdes pesquisadas, de modo a apresentá-las de acordo com as categorias nas quais se incluem. $O$ universo inicial era composto de 80 parques municipais, 03 parques estaduais e 1 estação ecológica estadual, totalizando 84 áreas verdes. Contudo, devido à análise de fragmentos e conexões na parte de preparo da atividade de campo, verificou-se a necessidade de ampliar a quantidade de áreas verdes pesquisadas. Ao final foram cadastradas 104 áreas verdes institucionalizadas.

O trabalho de campo foi organizado e dividido por região administrativa de Belo Horizonte, denominadas pela Prefeitura como Regionais Administrativas, que são nove: Barreiro, Oeste, Centro-Sul, Leste, Noroeste, Nordeste, Norte, Pampulha e Venda Nova.

Foi realizado um pré-campo para aferir e validar a prática proposta. Escolheu-se visitar 15 áreas verdes situadas nas Regionais Administrativas Nordeste e Pampulha, cujos espaços foram considerados como de preservação ambiental pela Lei Municipal 7.166/ 1996 que estabeleceu o uso e a ocupação do solo de Belo Horizonte. Neste pré-campo foram feitos os seguintes procedimentos: identificação da estrutura e dos espaços para cada área verde, caminhamento nos espaços buscando avaliar a cobertura vegetal existente através das suas tipologias, os equipamentos instalados e o uso e ocupação do espaço pela comunidade. Os espaços foram fotografados, e quando necessário obtido as coordenadas geográficas dos locais, utilizando-se um receptor GPS - Sistema de Posicionamento Global. Este pré-campo teve a duração de dois dias e ocorreu nos dias 15 e 16 de agosto de 2013. Constatada a eficiência da metodologia empregada, foram realizadas visitas as áreas verdes das demais regionais administrativas (de 10 a 12 e em seguida de 24 a 27 de setembro de 2013).

Em campo foram utilizados, dentre outros equipamentos, um receptor GPS de navegação da marca Garmim Etrex (versão 2.70), bússola e material cartográfico relevante, dentre os quais pode-se citar: mapas de campo elaborados para cada Regional Administrativa com imagens do satélite quickbird na escala de 1:5.000 (de 2008). Antes da ida a campo foram realizadas varreduras visuais para identificar outras áreas verdes expressivas na trama urbana nos mapas de campo, além das já categorizadas no universo inicial. Foi feito o registro fotográfico que viria complementar o conjunto de informações. 
É importante destacar que para realizar as pesquisas nos parques municipais de Belo Horizonte foi solicitado autorização junto à Fundação de Parques Municipais/ PBH.

\section{Tratamento da Informação Espacial}

Esta etapa possibilitou o cruzamento das informações e a busca em responder aos objetivos específicos desta pesquisa. Foram realizadas análises a partir dos levantamentos de campo com o objetivo de entender a dinâmica das áreas verdes da capital mineira. A partir daí, foi elaborada uma coletânea de mapas temáticos para o município investigado. Para a classificação das áreas verdes institucionalizadas, foi utilizado o cálculo de área do programa ArcGis e, em seguida, com a ferramenta de quebra natural (Natural Breaks) feita a classificação de acordo com as suas dimensões.

As bases de dados geográficas usadas nos mapas temáticos foram fornecidas pela PRODABEL, FPM e SMAPU, órgãos da Prefeitura de Belo Horizonte, bem como, do Instituto Estadual de Florestas (IEF/SISEMA) e da Secretaria de Estado de Desenvolvimento Regional e Política Urbana (SEDRU), ambos do Governo de Minas Gerais.

Para a elaboração do mapa temático que apresenta proposta de raios de influência das áreas verdes institucionalizadas, utilizou-se a ferramenta de buffer do programa ArcGis, de acordo com as referências indicadas por Ribeiro et al. (2009) e Tabarelli et al. (2010), para raio de 100 metros, Feliz (2013) para o raio de 300 metros, e Krier e Carvalho (1999) e Colin (2013) para o raio de 600 metros.

A base de dados sobre a cobertura vegetal utilizada foi fornecida pelo IEF/ SISEMA. Esta base de dados foi elaborada a partir de imagens de satélite do ano de 2009 para todo o Estado de Minas Gerais, tendo sido realizado o recorte para a área da pesquisa.

Para a análise dos dados foram utilizadas as medidas das estruturas de paisagem propostas por Lang e Blaschke (2009), contendo a quantificação dos dados de áreas, as categorias, a forma de gestão, os raios de influência e outras possíveis conexões. Para os autores citados, as estruturas e os padrões utilizados são manifestações espaciais / temporais de processos que ocorrem em diferentes escalas. Por isto, as ferramentas utilizadas em microcomputadores que desenvolvem métodos do processamento de informações geográficas, bem como do processamento digital de imagens, são fundamentais para a análise da estrutura da paisagem. As informações tratadas vieram complementar o banco de dados criado para as áreas verdes institucionalizadas e foi determinante para a realização dos mapas temáticos apresentados neste artigo, que visaram à detecção, à construção da análise e à avaliação das características e da dinâmica espacial dessas áreas. 


\section{RESULTADOS E DISCUSSÃO}

Foram cadastradas cento e quatro áreas verdes consideradas institucionalizadas. Destas, sessenta e quatro foram enquadradas como áreas destinadas à conservação e vinte e três áreas destinadas exclusivamente para o lazer. Estas últimas são consideradas parques municipais pela FPM/ PBH. Embora tenham esta classificação não possuem atrativos naturais ou cobertura vegetal relevante, sendo utilizados como praças públicas. O que evidência o uso da terminologia de forma imprópria conforme já destacado por Buccheri Filho e Nucci (2006). Por fim, dezessete foram classificados como áreas em processo de reabilitação. Dessas, doze áreas voltadas para a conservação da paisagem, delas entram na categoria de uma para lazer e, para as outras quatro existe a possibilidade de tornarem-se áreas também destinadas à conservação embora essa destinação ainda não esteja definida pela Prefeitura. Todas estas dezessete áreas são consideradas "parques municipais não implantados" pela FPM/ PBH. O mapa da Figura 2 mostra a espacialização das cento e quatro áreas verdes cadastradas segundo a categoria proposta.

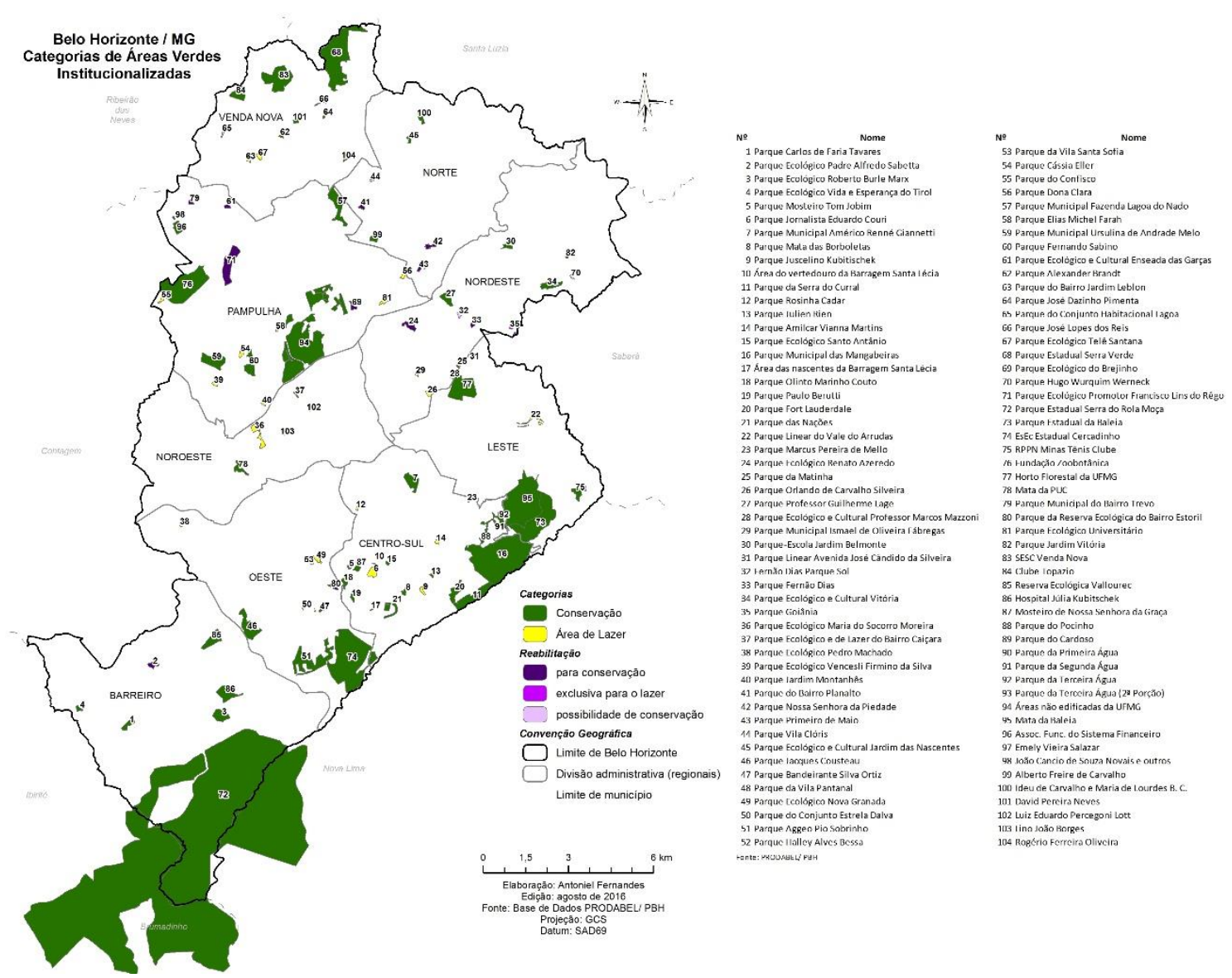

Figura 2. Mapa das Categorias de Áreas Verdes Institucionalizadas de Belo Horizonte/ MG Figure 2. Map of Institutionalized Categories of Green Areas of Belo Horizonte/MG 
A Regional Administrativa Centro-Sul destaca-se pelo maior número de áreas destinadas à conservação, contabilizando vinte e uma áreas. Na Regional Administrativa Norte o número dessas unidades são três, enquanto na Regional Administrativa Venda Nova são oito. Entre as áreas destinadas exclusivamente ao lazer, destacam-se aquelas situadas na Regional Administrativa Pampulha, que possui sete unidades. As Regionais Administrativas Barreiro e Norte não possuem espaços destinados ao lazer.

Em termos de reabilitação de espaços verdes já transformados em parques municipais pela Prefeitura Municipal de Belo Horizonte (instituídos por legislação municipal) destaca-se a Regional Administrativa Nordeste, com cinco unidades. As Regionais Administrativas Centro-Sul e Leste não possuem espaços para reabilitação. A Tabela 1 mostra a distribuição das áreas verdes institucionalizadas entre as nove Regionais Administrativas da cidade de Belo Horizonte.

Tabela 1. Distribuição das Áreas Verdes por Regional Administrativa em BH/ MG (2013) Table 1. Distribution of Green Areas for Administrative Regions of BH/MG (2013)

\begin{tabular}{c|c|c|c}
\hline REGIONAL & CONSERVAÇÃO & LAZER & REABILITAÇÃO \\
\hline Barreiro & 7 & 0 & 1 \\
Centro-Sul & 21 & 4 & 0 \\
Leste & 4 & 1 & 0 \\
Nordeste & 6 & 3 & 5 \\
Noroeste & 4 & 1 & 0 \\
Norte & 3 & 0 & 4 \\
Oeste & 5 & 5 & 1 \\
Venda Nova & 8 & 2 & 2 \\
Pampulha & 7 & 7 & 4 \\
\hline Total & $\mathbf{6 5}$ & $\mathbf{2 3}$ & $\mathbf{1 7}$ \\
\hline
\end{tabular}

Das áreas verdes investigadas, conforme demonstra a Tabela 2, oitenta e três são classificadas como parques, dos quais oitenta são geridos pelo município e três pelo Estado de Minas Gerais através do Instituto Estadual de Florestas (IEF). O Estado também faz a gestão de uma Estação Ecológica (EsEc Cercadinho), que é responsável por parte do abastecimento de água do município e de um hospital (Júlia Kubitschek) que possui área verde expressiva e preservada, situada na Regional Administrativa Barreiro. 
Tabela 2. Gestão das Áreas Verdes Institucionalizadas em Belo Horizonte/ MG (2013)

Table 2. Management of Institutionalized Green Areas of Belo Horizonte/MG (2013)

\begin{tabular}{|c|c|c|c|}
\hline GESTÃO & TIPO & QUANTIDADE & $\begin{array}{l}\text { PROPRIEDADE / LOCALIZAÇÃO } \\
\text { (REGIONAL ADMINISTRATIVA) }\end{array}$ \\
\hline Municipal & $\begin{array}{c}\text { Parques } \\
\text { Fund. Zoobotânica }\end{array}$ & $\begin{array}{c}80 \\
1\end{array}$ & $\begin{array}{c}\text { PBH } \\
\text { PBH/ Pampulha }\end{array}$ \\
\hline Estadual & $\begin{array}{c}\text { Parques } \\
\text { Estação Ecológica } \\
\text { Hospital } \\
\end{array}$ & $\begin{array}{l}3 \\
1 \\
1\end{array}$ & $\begin{array}{l}\text { Serra Verde, Serra do Rola Moça e } \\
\text { Cercadinho / Centro-sul } \\
\text { Hospital Julia Kubitscheck / Barreiro }\end{array}$ \\
\hline Federal & $\begin{array}{l}\text { Universidade } \\
\text { Horto Florestal }\end{array}$ & $\begin{array}{l}1 \\
1\end{array}$ & $\begin{array}{c}\text { campus UFMG / Pampulha } \\
\text { UFMG / Leste }\end{array}$ \\
\hline Particular & $\begin{array}{c}\text { RPPN } \\
\text { RPE } \\
\text { Hospital } \\
\text { Universidade } \\
\text { Mosteiro } \\
\text { Reserva Florestal } \\
\text { Clube recreativo }\end{array}$ & $\begin{array}{l}1 \\
9 \\
1 \\
1 \\
1 \\
1 \\
2\end{array}$ & $\begin{array}{c}\text { Minas Tênis Clube / Leste } \\
\text { Hospital da Baleia / Leste } \\
\text { PUC-Minas - Igreja Católica / Nordeste } \\
\text { Igreja Católica / Centro-sul } \\
\text { Vallourec Tubos do Brasil / Barreiro } \\
\text { Clube Topázio e SESC / Venda Nova }\end{array}$ \\
\hline Total & & 104 & \\
\hline
\end{tabular}

A Prefeitura Municipal de Belo Horizonte também mantém expressiva área verde preservada no terreno ocupado atualmente pela Fundação Zoobotânica na região da Pampulha. $\mathrm{Na}$ esfera Federal, destacam-se as áreas não edificadas do campus da Universidade Federal de Minas Gerais (UFMG), definidas no Plano Diretor da Universidade, também situadas na Regional Administrativa Pampulha, e o Horto Florestal, localizado na Regional Administrativa Leste.

Entre as áreas verdes localizadas em propriedade particular, destacam-se os vinte hectares de vegetação contidas na Reserva Florestal da Empresa Siderúrgica Vallourec Tubos do Brasil, localizada na Regional Administrativa Barreiro, e treze hectares da Reserva Particular do Patrimônio Natural (RPPN) do Minas Tênis Clube localizado à extremo leste do município, na Regional Administrativa Leste. Os fragmentos menores são constituídos por Reservas Particulares Ecológicas (RPEs) que, somados, totalizam nove e possuem aproximadamente vinte e dois hectares.

As RPEs foram criadas e são institucionalizadas pelo município de Belo Horizonte através da Lei Municipal $n^{\circ} 6.314 / 93$ que define em seu artigo $1^{\circ}$ "qualquer pessoa, física ou jurídica, poderá requerer ao executivo que institua em imóvel de propriedade da mesma Reserva Particular Ecológica, por reconhecê-la como de valor ecológico, total ou parcialmente". Esta Lei determina ainda no parágrafo único deste artigo "somente poderá ser reconhecido como RPE o imóvel particular onde sejam identificadas condições naturais primitivas ou semiprimitivas recuperadas ou cujas características justifiquem ações de recuperação, pelo aspecto 
paisagístico, para a preservação do ciclo biológico de espécies da fauna ou da flora nativas do Brasil".

No tocante ao prazo de validade de uma RPE, a referida lei institui que a vigência nunca deverá ser inferior a vinte anos, e preferencialmente em caráter perpétuo, sendo definido pelo proprietário. Um ponto interessante da lei prevê a rescisão do termo de compromisso fundamentada em interesse público relevante ou por descumprimento de cláusulas por força de lei, ou seja, caso o proprietário ou demais pessoas causarem alterações nas características da área, está perderá o título de Reserva Particular Ecológica, cabendo aos envolvidos motivadores do dano a rescisão antecipada do termo de compromisso e a responder criminalmente pela sua ocorrência.

Há também duas áreas verdes de propriedade da Igreja Católica em Belo Horizonte, uma das quais, encontra-se no campus da PUC-Minas (aproximadamente oito hectares) e outra no Mosteiro de Nossa Senhora da Graça (aproximadamente cinco hectares) situado no bairro Vila Paris nas proximidades da Barragem Santa Lucia, na Regional Administrativa Centro-Sul.

Foram também identificadas áreas verdes preservadas no Clube Recreativo Topázio e no SESC Venda Nova, com aproximadamente quatorze e sessenta hectares, respectivamente, ambos situados na Regional Administrativa Venda Nova. Além de outro hospital mapeado (Hospital da Baleia) com expressiva área verde, gerido por uma organização não governamental (Fundação Benjamin Guimarães). O contato dos doentes com a Natureza e a pureza do ar existente nas áreas verdes e ao redor, em meio às quais estes hospitais estão situados, contribuem para o tratamento de enfermidades, principalmente a tuberculose, conforme consulta aos sites eletrônicos das Instituições. Ambos os hospitais (Hospital da Baleia e Hospital Júlia Kubitschek) foram implantados em meados do século XX em regiões, até então, pouco habitadas de Belo Horizonte (COSTA et al., 2009). O mapa da Figura 3 mostra a espacialização destas áreas verdes, de acordo com a sua localização no município e em cada Regional Administrativa. 


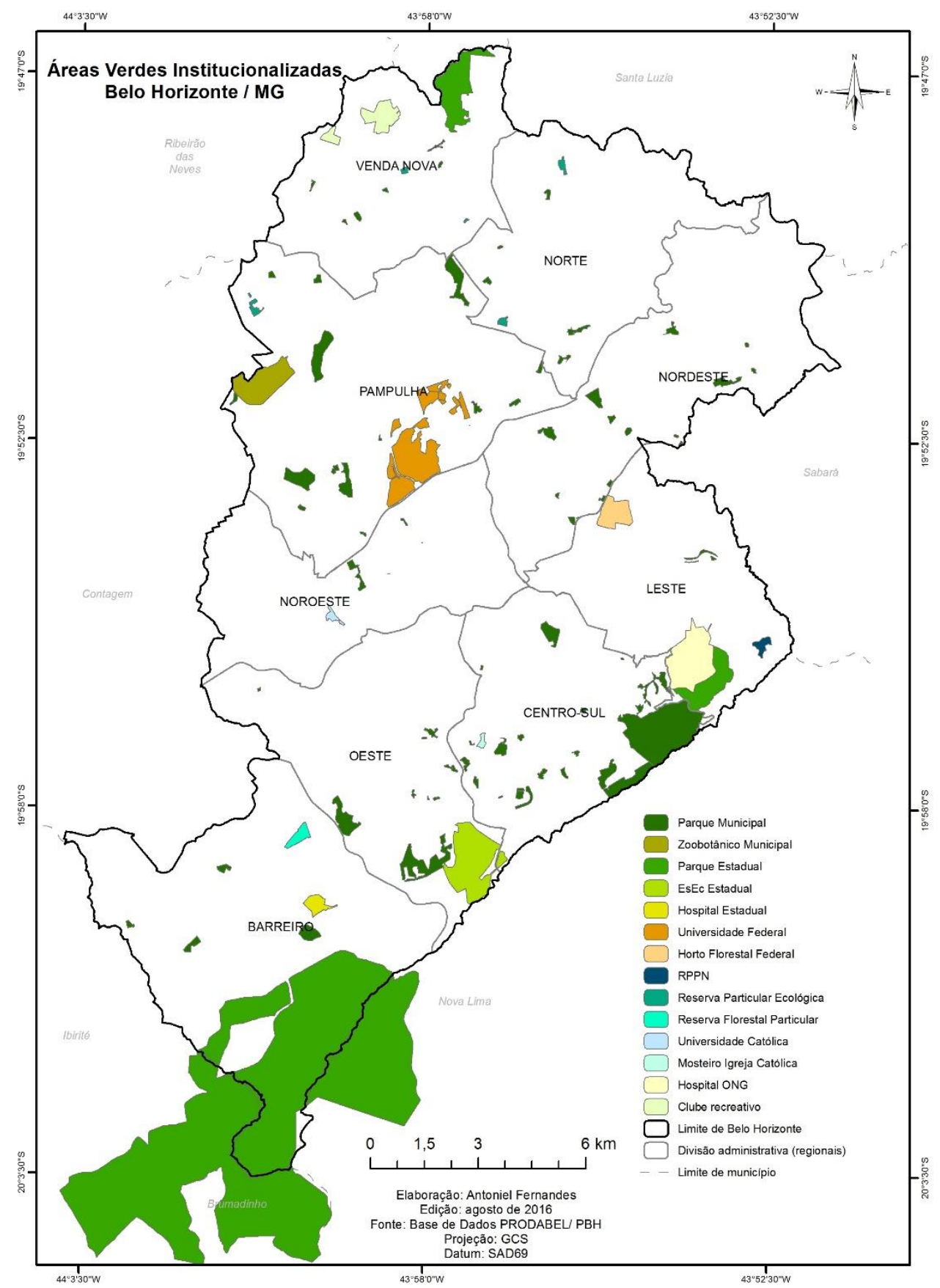

Figura 3. Mapa das Áreas Verdes Institucionalizadas de Belo Horizonte/ MG Figure 3. Map of Institutionalized Green Areas of Belo Horizonte/MG

Entre as cento e quatro áreas verdes investigadas, setenta e cinco possuem dimensão entre dois ares $\left(200 \mathrm{~m}^{2}\right)$ e oito hectares e, treze delas possuem entre nove e vinte e cinco hectares. O mapa apresentado na Figura 4 mostra que a maior parte das áreas verdes institucionalizadas tem dimensões inferiores a dez hectares. As manchas pequenas expõem esses fragmentos à ocorrência de efeito de borda, que irá alterar, dentre outros, a composição e/ ou abundância relativa de espécies (LANG; BLASCHKE, 2009). Ainda os autores ressaltam 
que quando os fragmentos são pequenos ou há um forte efeito de borda não haverá área núcleo remanescente.

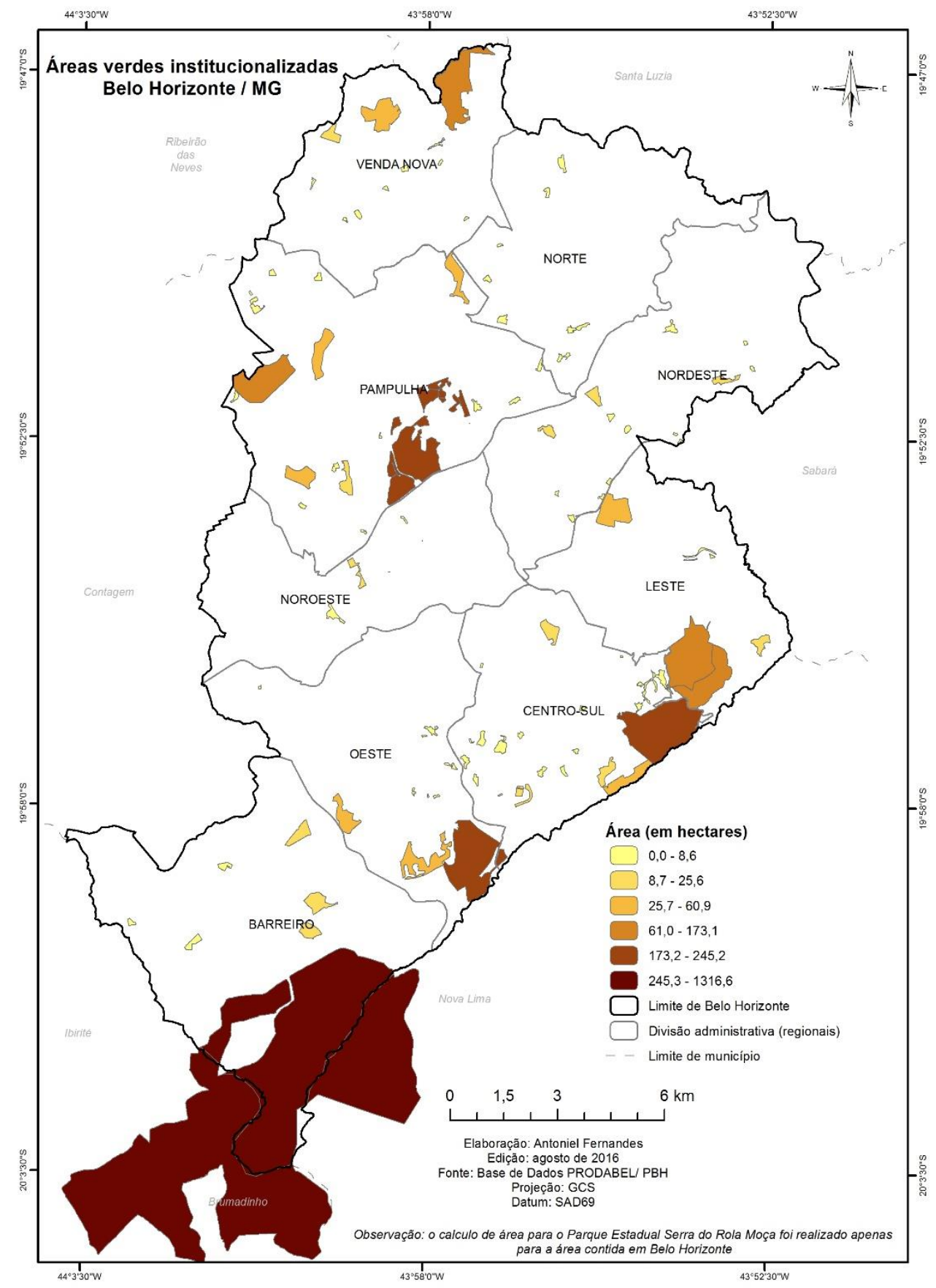

Figura 4. Mapa das Áreas Verdes Institucionalizadas de Belo Horizonte (MG) classificadas por sua dimensão em hectares

Figure 4. Map of Institutionalized Green Areas of Belo Horizonte (MG) ranked by their size in hectares

As maiores áreas estão concentradas na Serra do Curral, no extremo Sul do município de Belo Horizonte e na região da Pampulha, estes últimos devido à existência das áreas verdes da UFMG e da Fundação Zoobotânica. Além dessas, o Parque Estadual Serra Verde, no extremo Norte de Belo Horizonte, está entre as maiores. 
Foi calculada também a área das Zonas de Preservação Ambiental (ZPAMs) cuja soma resulta em 11,89\% em relação à área total do município de Belo Horizonte. A área total das áreas verdes institucionalizadas é de $10 \%$ em relação à área total do município. Costa et al. (2009) lembra que nem todas as áreas verdes institucionalizadas encontram-se incorporadas à Lei de Uso e Ocupação do Solo do município como Zonas de Preservação Ambiental (ZPAM). Existem aproximadamente $2 \%$ das áreas verdes institucionalizadas que fazem parte de outras zonas (ZP1, ZP-2, ZP-3, ZE, ZEIS-1, ZAR-2, ZCVN e ZAP3). Costa et al. (2009) e Oliveira (2010) salientam que as áreas verdes instituídas como Zonas de Preservação Ambiental pela LUOS de Belo Horizonte garantem maior proteção e preservação desses fragmentos, uma vez que é vedada a ocupação em áreas definidas como ZPAMs. A tabela 3 sintetiza os cálculos realizados.

Tabela 3. Áreas Protegidas em Belo Horizonte/ MG (2013) ${ }^{1}$

Table 3. Protected Areas in Belo Horizonte/MG (2013) ${ }^{1}$

\begin{tabular}{cccc}
\hline & ÁREA (ha) & ÁREA (km²) & $\begin{array}{c}\text { \% no } \\
\text { MUNICíPIO }\end{array}$ \\
\hline ZPAM & $3.938,2655$ & 39,38 & 11,89 \\
Áreas verdes institucionalizadas & $3.312,5878$ & 33,13 & 10,00 \\
Áreas verdes institucionalizadas em ZPAM & $2.523,6615$ & 25,24 & 7,62 \\
Áreas verdes institucionalizadas em outras zonas & 788,9263 & 7,89 & 2,38 \\
Demais áreas de ZPAM & $1.414,6040$ & 14,15 & 4,27 \\
\hline Área de Belo Horizonte & $\mathbf{3 3 . 1 1 7 , 7 8 5 4}$ & $\mathbf{3 3 1 , 1 8}$ & - \\
\hline
\end{tabular}

1: Todos os cálculos de área foram extraídos do ArcGis 9.3

Fonte: Dados consolidados pelo autor, 2013

Além disso, existem áreas consideradas como ZPAM que não são áreas verdes institucionalizadas e que correspondem a $14,15 \mathrm{~km}^{2}$ ou $4,27 \%$ do município de Belo Horizonte. Algumas dessas áreas possuem expressivas manchas verdes e apresentam potencial para serem destinados à criação de parques voltados para o lazer e a conservação, principalmente na porção extremo nordeste das Regionais Administrativas Norte e Nordeste (OLIVEIRA, 2010).

Nestas áreas a cobertura vegetal é relevante e ainda há baixo adensamento populacional, conforme pode ser observado nos bancos de dados sobre densidade demográfica de Belo Horizonte, realizados pelo Censo de 2010. Partes dessas áreas já se encontram previstas na LUOS como áreas de preservação (ZPAMs) conforme demonstrado na figura 5.

\footnotetext{
${ }^{3}$ Segundo a Lei 7.166 de 27 de agosto de 1996 o território de Belo Horizonte é dividido em zonas diferenciadas segundo os potenciais de adensamento e as demandas de preservação e proteção ambiental, histórica, cultural, arqueológica ou paisagística. A seguir é apresentado o significado das siglas citadas: ZP - Zona de Proteção, ZE - Zona de Grandes Equipamentos, ZEIS - Zona de Especial Interesse Social, ZAR - Zona de Adensamento Restrito, ZCVN - Zona Central de Venda Nova e ZAP - Zona de Adensamento Preferencial.
} 


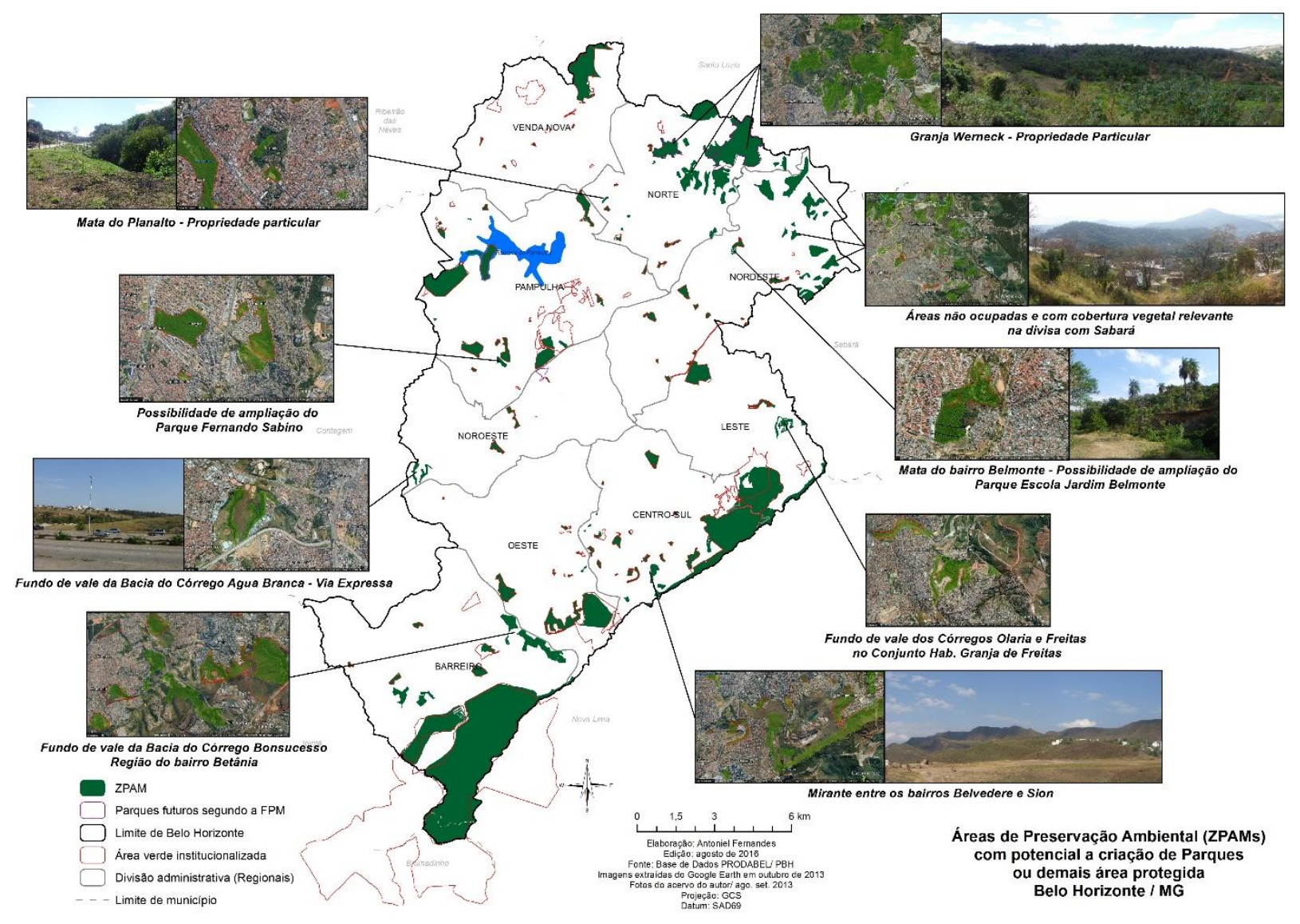

Figura 5. Mapa das Áreas de Preservação Ambiental (ZPAMs) com potencial para a criação de parques ou demais áreas protegidas de Belo Horizonte/ MG

Figure 5. Map of Environmental Preservation Areas [Zonas de Preservação Ambiental (ZPAMs)] (Environmental Preservation Zone) with the potential for creating parks or other protected areas in Belo Horizonte/MG

Ainda sobre as áreas verdes com potencial para criação de áreas protegidas, a Prefeitura Municipal de Belo Horizonte possui proposta de criação de futuros parques em duas áreas de ZPAMs, a extremo nordeste da Regional Administrativa Norte, na região conhecida como Granja Werneck, conforme identificado no mapa da figura 5.

\section{Os Eixos verdes em Belo Horizonte}

$\mathrm{Na}$ constituição de rede de conexão entre as áreas verdes a distância desempenha um papel essencial, pois é fator decisivo na configuração espacialmente explícita de hábitats adequados (LANG; BLASCHKE, 2009). Para identificar os raios de influência entorno das áreas verdes investigadas foram realizados círculos (Buffer) conforme apresentado anteriormente, o resultado encontra-se indicado no mapa da Figura 6. 


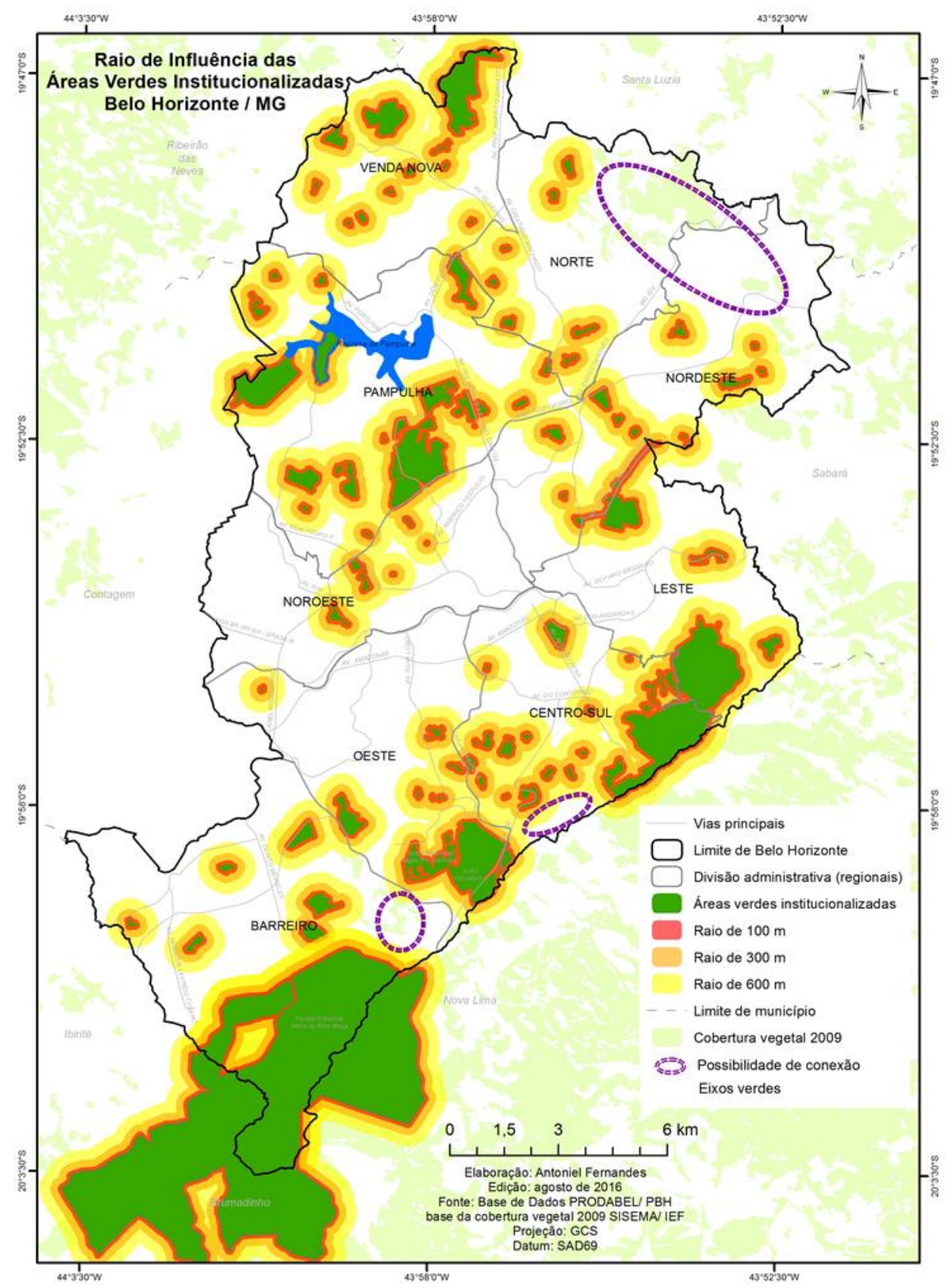

Figura 6: Resultado da aplicação dos raios de influência das Áreas Verdes Institucionalizadas de Belo Horizonte/ MG

Figure 6. Results of the influence rays application for Institutionalized Green Areas in Belo Horizonte/MG

Ao analisar este mapa observa-se um conjunto de áreas verdes protegidas ao longo da Serra do Curral, formando um "eixo verde" de proteção na porção extremo sul de Belo Horizonte, no sentido sudoeste/ leste. Apesar de não ser um corredor contínuo, existem áreas de grande potencial para a criação de parques e/ ou demais áreas a serem protegidas, entre o Parque Estadual da Serra do Rola Moça, situado na Regional Administrativa Barreiro, e áreas protegidas localizadas a extremo sul da Regional Administrativa Oeste, como a Estação Ecológica Estadual Cercadinho e o Parque Municipal Aggeo Pio Sobrinho. 
É ainda possível uma ampliação das áreas protegidas situadas nas partes extremas da Regional Administrativa Centro-Sul, para a criação de outros parques ou novas áreas protegidas além daquelas já estabelecidas pela LUOS, destinadas à preservação e / ou proteção ambiental (ZPAMs e ZPs).

A pesquisa observou, ainda, que outro "eixo verde" poderá ser formado no sentido sudeste-noroeste, iniciando-se na Regional Administrativa Nordeste, na divisa com o município de Sabará, passando pelos limites das regionais administrativas Norte e Pampulha, até atingir o extremo norte da Regional Administrativa Venda Nova. Há, também, a possibilidade de se institucionalizar dois eixos menores perpendiculares a este eixo principal, no sentido sudoeste: o primeiro na Av. José Cândido da Silveira, que conecta o Parque Linear desta via à quatro parques municipais e ao Horto Florestal e, o segundo, que acompanha o lado norte do Anel Rodoviário, onde se encontram as áreas não edificadas do campus da UFMG.

Os dois principais eixos de conexão verde apontados nesta pesquisa são os principais elos entre os fragmentos verdes existentes em Belo Horizonte com os dos municípios circunvizinhos, corroborando Oliveira (2010).

Verificou-se que as divisas das Regionais Administrativas Nordeste, Noroeste, Oeste, Centro-sul e Leste, situadas na porção central do município de Belo Horizonte, constituem-se por um "vazio", uma ausência de áreas verdes. O motivo da ausência de áreas verdes neste espaço deve-se à ocupação desta porção logo nos primeiros anos após a construção desta cidade. Ali surgiram os bairros da Lagoinha, Floresta, Bonfim e São Cristovão, onde se estabeleceu boa parte da população que participou da construção da Capital (COSTA et al., 2009). Vale ressaltar que existe também uma carência de áreas verdes nas porções do extremo oeste da Regional Administrativa Noroeste e nas Regionais Administrativas Barreiro e Leste, onde não há parques ou demais áreas protegidas.

\section{CONCLUSÕES}

As áreas verdes investigadas são constituídas, em sua maioria, por parques municipais, de dimensões muito pequenas (em média de um a três hectares fragmentados no tecido urbano), com pouca possibilidade de conexão entre si, sem a realização de grandes intervenções urbanísticas. Os espaços verdes constituídos por parques destinados à conservação ambiental são, em sua maioria, espaços fechados, que possuem pequenas porções destinadas ao uso dos habitantes para lazer. A forma adequada de uso destes espaços verdes seria por meio da abertura completa destes espaços para a comunidade, conduzida por programas de educação ambiental e visitas guiadas, de modo a sensibilizar a população. 
Entre as áreas verdes investigadas pôde-se perceber que as situadas ao sul de Belo Horizonte formam um "eixo verde" com sentido Sudoeste/ Leste nas vertentes da Serra do Curral. Este eixo permite a troca genética das espécies da fauna e da flora e o deslocamento das mesmas para além deste município. A região do bairro Lagoinha e do seu entorno próximo à área central de Belo Horizonte, constitui-se como uns dos principais pontos onde foi verificada a ausência de áreas verdes. Constatou-se que as áreas verdes situadas na porção a extremo nordeste das Regionais Administrativas Norte e Nordeste são relevantes e com grande potencial para a criação de parques e áreas protegidas.

Este estudo possibilitou entender a distribuição dos espaços verdes de Belo Horizonte, foco do objetivo desta pesquisa, o que foi alcançado principalmente a partir da metodologia utilizada através da categorização das áreas verdes investigadas. Por fim, recomenda-se que a gestão dos espaços verdes deve contar com ações privadas a fim de viabilizar a criação, gestão e manutenção destes espaços. Portanto, a valorização, e a ampliação das Reservas Particulares Ecológicas devem partir da Secretaria Municipal de Meio Ambiente, conscientizando os proprietários de áreas relevantes sobre a necessidade de conservação áreas permanentemente protegidas em Belo Horizonte.

\section{AGRADECIMENTOS}

Agradecimento à Fundação de Amparo à Pesquisa do Estado de Minas Gerais (FAPEMIG) por financiar parte desta pesquisa.

\section{REFERÊNCIAS}

BARGOS, D. C.; MATIAS, L. F. Áreas verdes urbanas: um estudo de revisão e proposta conceitual. Revista da Sociedade Brasileira de Arborização Urbana, Piracicaba, v. 6, n. 3, p.172-188, 2011.

BUCCHERI FILHO, A. T.; NUCCI, J. C. Espaços Livres, Áreas Verdes e Cobertura Vegetal no Bairro Alto da XV, Curitiba/PR. Revista do Departamento de Geografia da Faculdade de Filosofia, Letras e Ciências Humanas da Universidade de São Paulo, São Paulo, v. 18, n.1 p.48-59, 2006.

COLIN, S. Novo Urbanismo. Disponível em: <http://coisasdaarquitetura.wordpress.com/ 2010/07/18/novo-urbanismo/>. Acesso em: 01 nov. 2013.

COSTA, R. G. S.; COLESANTI, M. M. A contribuição da percepção ambiental nos estudos das áreas verdes. Revista Ra'e Ga - O Espaço Geográfico em Análise. Curitiba v. 22, n.2 p. 238$251,2011$. 
COSTA, S. A. P.; ÁlVARES, L.C.; MACIEL, M. C.; TEIXEIRA, M. C. V.; COIMBRA, V. B. C.; SIMÃO, K. M. C.; PERNA, S. A.; GODINHO, L. R. Os espaços livres na paisagem de Belo Horizonte. Paisagem ambiente, São Paulo, v.1 n. 26, p. 51-72, 2009.

FELIZ, M. Cidade sustentável: uma abordagem sistêmica. Belo Horizonte: FEAM, 2013. 278.

HUNTER, P. The human impact on biological diversity. EMBO reports, Malden, v. 8, n. 4, p. 316318, 2007.

KRIER, L.; CARVALHO, A. S. R. Arquitectura: escolha ou fatalidade. Lisboa: Estar, 1999. 208 p.

LANG, S.; BLASCHKE, T. Análise da paisagem com SIG. São Paulo: Oficina de Textos, 2009. $424 \mathrm{p}$.

MAZZEI, K; COLESANTI, M T. M; SANTOS, D. G DOS. Áreas verdes urbanas, espaços livres para o lazer. Revista Sociedade \& Natureza, Uberlândia, v. 19, n. 1, p. 33-43, 2007.

MOREIRA, J. F. R; SILVA, C. A DA. Paisagem urbana e áreas verdes: contexto dos parques urbanos de Goiânia. Boletim Goiano de Geografia, Goiânia, v. 32, n. 2, p. 239-254, 2012.

OLIVEIRA, A. M. O Verde na Cidade: Uma Aproximação ao Planejamento da Rede de Espaços Verdes de Belo Horizonte, Brasil. Barcelona, 2010. 84f. Dissertação (Mestrado em Planificação Territorial e Gestão Ambiental) - Universidade de Barcelona, Barcelona, 2010.

RIBEIRO, M. C.; METZGER, J. P.; MARTENSEN, A. C.; PONZONI, F. J.; HIROTA, M. M. The Brazilian Atlantic Forest: How much is left, and how is the remaining forest distributed? Implications for conservation. Biological Conservation. Boston, v. 142, n. 6, p. 1141-1153, 2009.

SHAMS, J. C. A.; GIACOMELI, D. C.; SUCOMINE, N. M. Emprego da arborização na melhoria do conforto térmico nos espaços livres públicos. Revista da Sociedade Brasileira de Arborização Urbana, Piracicaba, v. 4, n. 4, p.1-16, 2009.

TABARELLI, M.; AGUiAR, A. V.; RIBEIRO, M. C.; METZGER, J. P.; PERES, C. A. Prospects for biodiversity conservation in the Atlantic Forest: Lessons from aging human-modified landscapes. Biological Conservation. v. 143, n. 10, p. 2328-2340, 2010. 